\title{
LA PRUEBA DE LA INOCENCIA Y LAS DEFENSAS PROBATORIAS: EL CASO DE LA REVISIÓN*
}

\section{PROOF OF INNOCENCE AND EVIDENTIARY DEFENCES: THE CASE OF THE REMEDY OF REVISION}

\author{
Flavia Carbonell Bellolio** \\ Jonatan VALENZUELa SALDias ${ }^{* * *}$
}

\begin{abstract}
RESUMEN: A partir de una conceptualización del razonamiento defensivo en los procesos judiciales, el trabajo analiza el rol de las defensas probatorias en el proceso penal. Dentro de este tipo de defensas, la alegación de la inocencia en el contexto de la acción de revisión revive la discusión teórica sobre los distintos estándares probatorios disponibles en el proceso penal. El estudio de la práctica de la Corte Suprema chilena sobre este punto, a su vez, revela algunas contradicciones y problemas de sobrevaloración de la prueba científica aportada para probar la inocencia de una persona (erróneamente) condenada por sentencia firme. Este trabajo persigue mostrar la necesidad de contar con un estándar probatorio para la inocencia que sirva de coordenada para su prueba en la revisión en particular y en el proceso penal en general.
\end{abstract}

Palabras clave: proceso penal, prueba, defensas, acción de revisión.

ABSTRACT: This work analyses the role of evidentiary defences in criminal procedures using a general conceptual framework of defensive reasoning in judicial procedures. Within this type of defences, the claim of innocence in the Chilean regulation of the remedy of revision revives the theoretical debate concerning different standards of proof in criminal procedures. The study of decisions of the Supreme Court on this matter, in turn, reveals some contradictions and problems of overestimation of scientific or expert evidence offered to demonstrate the innocence of a (wrongly) convicted person by a final judgment. This work aims to show the need to have an evidentiary standard for innocence that serves as a coordinate for its proof in the remedy of revision in particular and in the criminal procedure in general.

Keywords: criminal trial, evidence, defences, revision action.

\footnotetext{
* Este artículo forma parte del Fondecyt Regular No 1191634, titulado "Error y proceso judicial", del que los autores son investigadora y coinvestigador, respectivamente. Los autores quisieran agradecer los comentarios de los árbitros anónimos, así como la dedicada labor de edición que nos proporcionó Ivana Peric.

** Licenciada en Ciencias Jurídicas y Sociales, Universidad de Concepción. Doctora en Derecho, Universidad Carlos III de Madrid. Profesora de Derecho Procesal, Universidad de Chile. Código Orcid: 0000-0001-6834043X. Dirección postal: Santa María 076, 50 piso, Santiago; Abdón Cifuentes 217, Santiago. E-mail: fcarbonell@derecho.uchile.cl.

*** Licenciado en Ciencias Jurídicas y Sociales, Universidad de Chile. Doctor en Derecho, Universidad de Girona. Profesor de Derecho Procesal, Universidad de Chile. Código Orcid: 0000-0002-9792-5637. Dirección Postal: Santa María 076, $5^{\circ}$ piso, Santiago; Capellán Abarzúa 95, Santiago. E-mail: jvalenzuela@derecho.uchile.cl.
} 


\section{CONSIDERACIONES PRELIMINARES}

Dos de los pilares fundamentales del proceso penal son el principio acusatorio y el principio de culpabilidad. En términos simplificados, corresponde al ente persecutorio probar la culpabilidad del imputado y si el tribunal estima que se ha superado el estándar probatorio "más allá de toda duda razonable", dictará sentencia condenatoria para sancionar a la persona culpable.

A la hipótesis acusatoria de culpabilidad se suma una hipótesis defensiva que, a diferencia de aquella, puede adoptar distintas modalidades: a) la negación de los hechos de la acusación; b) la aceptación de los hechos de la acusación pero cuestionando su calificación jurídica; c) la aceptación de los hechos de la acusación y de su calificación jurídica, pero incluyendo circunstancias modificatorias de la responsabilidad penal (atenuantes y/o eximentes); d) la alegación directa de la inocencia del imputado o acusado, incompatible con la hipótesis acusatoria.

Todas ellas son mecanismos defensivos que pueden desplegarse fundamentalmente en el juicio oral, durante la tramitación del recurso de nulidad o en la acción de revisión. Los dos últimos requieren, desde el punto de vista procesal, de actividad probatoria por parte de la defensa en juicio.

La acción de revisión es un escenario privilegiado para el estudio de las defensas que requieren actividad probatoria, ya que una de sus causales, que a su vez es la más alegada, exige presentar nuevas pruebas. Concretamente, cuando la causal se funda en la alegación de la inocencia de la persona condenada y, en un caso específico, cuando se exige la prueba de la inocencia a través de los medios establecidos por el legislador ${ }^{1}$.

Este artículo tiene por objeto ofrecer una conceptualización y clasificación genérica de las defensas en el proceso (1), para luego destacar algunas características del proceso penal que influyen en el modo en que se desarrolla el razonamiento defensivo en dicha sede (2). Este aparato conceptual será necesario para identificar el tipo de defensas que permiten dar por probada la inocencia. Seguidamente, se presentará la acción de revisión como escenario para explorar un tipo particular de defensas que denominaremos "defensas probatorias", y se abordará, desde el punto de vista teórico y práctico la prueba de la inocencia de un condenado por sentencia firme (3). La reflexión sobre prueba de la inocencia conducirá a descartar que deba aplicarse el mismo estándar de prueba que el fijado por el legislador para dar por probada la culpabilidad. El último apartado analizará críticamente las sentencias de la Corte Suprema chilena que han acogido la acción de revisión por la causal de la letra d) del artículo 473 del Código Procesal Penal, con especial atención al tipo de pruebas que se utiliza para fundar la inocencia (4). La hipótesis que se intentará verificar a través de este análisis es que la Corte Suprema chilena en las sentencias en las que ha acogido la acción de revisión fundada en la causal indicada, no reproduce el razonamiento utilizado para alcanzar sus conclusiones, no analiza las defensas presentadas para acreditar la inocencia y no se pronuncia sobre la regla de suficiencia probatoria que ha empleado, lo que muestra la necesidad y la urgencia de desarrollar una noción de estándar de prueba para la inocencia.

\footnotetext{
1 Código Procesal Penal, artículo 473 letra d).
} 


\section{LA CUESTIÓN CONCEPTUAL}

Tradicionalmente, la doctrina procesal se ha ocupado de las defensas en el proceso a través de dos vías. Una primera ha consistido en subsumir el concepto de "defensa" en el de "excepción", oponiendo este último al concepto de "acción". Las reflexiones sobre las excepciones han sido más bien técnicas y han dado lugar a clasificaciones sub-teorizadas a partir de la regulación positiva respectiva. Así ha ocurrido en la doctrina procesal chilena que, a partir de una definición de excepción como "toda defensa que el demandado opone a la pretensión jurídica del actor" ${ }^{2}$, esto es, como cualquier razón o argumento que se oponga a la petición fundada que el actor realiza al tribunal mediante una acción procesa ${ }^{3}$, ha elaborado distinciones entre excepciones nominadas e innominadas -según se encuentren o no previstas expresamente por el legislador- y entre excepciones dilatorias y perentorias -según su fundamento sea una cuestión de forma o de fondo- ${ }^{4}$. En ambos casos, y dentro de la estructura de un proceso contradictorio, el objetivo es impactar en la decisión de la sentencia y, más precisamente, en el juicio que afirma o niega la responsabilidad o culpabilidad de una de las partes. Las excepciones o defensa en tanto razones que se oponen a la pretensión del actor o a la acusación del ente persecutor se dirigen, pues, a impedir la condena $^{5}$ o a evitar la satisfacción total o parcial de la pretensión o acusación ${ }^{6}$. Los estudios sistemáticos sobre defensas y excepciones son casi inexistentes, y los que hay no profundizan en la cuestión conceptual ${ }^{7}$.

Una segunda vía asocia la noción de "defensa" al derecho a la defensa material, resguardado constitucional e internacionalmente a través de su regulación como parte de la garantía del debido proceso. Este derecho a la defensa "consiste en que las partes en un proceso civil (demandante y demandado) y los intervinientes en un proceso penal (imputado y víctima) puedan hacer uso de las oportunidades procesales y medios legales para acreditar la existencia de hechos que sirven de fundamento a las normas cuyas consecuencias jurídicas se persiguen a través del proceso, a proporcionar interpretaciones de los textos normativos aplicables al problema de relevancia jurídica en cuestión, a desvirtuar imputaciones de responsabilidad en su contra y a contradecir alegaciones de la otra parte o interviniente. Este derecho a presentar pretensiones ante tribunales que tengan por objeto la declaración o

\footnotetext{
2 Stoehrel (1995) p. 48.

3 Rodríguez caracteriza la excepción como la contracara de la acción que niega que la pretensión que aquella contiene sea conducente, RodríGuez (1995) p. 66.

4 Se trata de terminología que se usa en los procesos civiles entendidos como procesos no penales. Las excepciones perentorias, sustantivas o de fondo se dirigen a negar el fundamento de la pretensión, objetando los hechos que le sirven de base o afirmando nuevos hechos. Las excepciones dilatorias, adjetivas o de forma identifican vicios en el procedimiento, algunos de los cuales, de ser alegados y acogidos por el tribunal, impiden que el juicio siga tramitándose (CPC, artículo 303). En el ámbito del proceso penal, la regulación chilena permite al acusado deducir excepciones de previo y especial pronunciamiento, algunas que miran a la forma (incompetencia y litis pendencia) y otras al fondo (cosa juzgada, extinción de la responsabilidad penal, en Código Penal, artículo 93).

5 La expresión "condena" se aplica aquí tanto a sentencias penales como no penales, sentencias todas estimatorias de responsabilidad de una de las partes o intervinientes ("acusado" o "demandado" respectivamente).

6 Ortells (2001) pp. 315 y ss., y Couture (1958) pp. 89 y ss.

7 Véase, por ejemplo, Benabentos (1998).
} 
protección de un derecho, o la condena de un tercero, así como el derecho a protegerse de las pretensiones que se hagan valer en juicio se denomina, usualmente, derecho a la defensa material". El derecho a la defensa material incluiría, a lo menos: a) el derecho a ser oído dentro de un plazo razonable; ;) el derecho a formular alegaciones; c) el derecho a ofrecer y a rendir prueba; d) el derecho a contradecir alegaciones y prueba (bilateralidad); y e) el derecho a una sentencia motivada. En materia procesal penal, la regulación positiva internacional es incluso más detallada.

Estas vías para abordar la noción de "defensa" en el proceso, sin embargo, no permiten visibilizar ni identificar, ya sea por estrechez o por amplitud, los distintos mecanismos defensivos que operan en un proceso judicial ni menos sistematizarlos de acuerdo con determinados criterios. La primera perspectiva asocia la noción de defensa a los argumentos de diversa naturaleza con los que cuenta el demandado para negar plausibilidad total o parcial a la pretensión del demandante, y que puede esgrimir en diversas oportunidades procesales. La segunda perspectiva configura el derecho de la defensa como un derecho que los jueces se encuentran obligados a respetar, ya que forma parte de la garantía del debido proceso como mecanismo de control frente al ejercicio de la jurisdicción.

Desde otra vereda, la filosofía jurídica se ha ocupado tempranamente de la idea de defensas, excepciones y excusas a propósito de la adscripción de responsabilidad ${ }^{10}$, de la noción de "derrotabilidad", del carácter general de las normas jurídicas y de la posibilidad de identificar a priori todas las condiciones necesarias y suficientes para su aplicabilidad. En la literatura reciente destacan los trabajos de Gardner y Duarte d'Almeida.

A partir de la estipulación de una definición de derrotabilidad ${ }^{11}$, Duarte d'Almeida ofrece una diferenciación entre "excepciones" y "defensas"12. Este autor propone separar conceptualmente, por una parte, aquella clase de hechos relevantes cuya consideración impacta en cualquier decisión judicial (a los que llama hechos-P y hechos- $\mathrm{D}^{13}$ ), y por otra, aquellos hechos que en cada caso concreto concurren y que el juez debe considerar al adoptar su decisión. Así, y alejándose de la terminología de la dogmática procesal, reserva "excepción" para dar cuenta de los hechos relevantes, incluidas las circunstancias de derrotabilidad o hechos-D, cuya identificación permite la construcción de una regla general compleja que incluya a priori las condiciones necesarias y suficientes para obtener una decisión correcta. Y emplea el término "defensa" para referirse a las objeciones, contraargumentaciones o respuestas que esgrime cualquier persona que, en el contexto de un proceso, es confrontada con afirmaciones o acusaciones $\operatorname{concretas}^{14}$.

\footnotetext{
8 Carbonell y Letelier (2020) p. 36.

9 Convención Americana de Derechos Humanos, San José (22 de noviembre de 1969) artículo 8.1; y Pacto Internacional de Derechos Políticos y Civiles, Nueva York (16 de diciembre de 1966) artículo 14.1.

10 Hart (1949) y (1957).

11 Duarte d'Almeida (2015b) p. 29.

12 Duarte d’Almeida (2015b).

13 En palabras del autor, ' $\mathrm{P}$ ' representa la conjunción $\left(\mathrm{P}_{1}\right.$ y $\mathrm{P}_{2} \mathrm{y} \ldots \mathrm{P}$ ) de aquellos elementos cuya presencia es requerida para la decisión del juez (“condiciones necesarias”, en la terminología de Hart) y 'D' representa la disyunción $\left(\mathrm{D}_{1} \mathrm{y}_{2} \mathrm{y} \ldots \mathrm{D}_{\mathrm{n}}\right)$ de las excepciones admisibles. Ambas clases de hechos pueden ser positivos o negativos, DUARTE (2015b) p. 50.

14 Véase también Duarte D'Almeida (2015a).
} 
Siguiendo a Fletcher y Gardner, Duarte d'Almeida se propone distinguir entre defensa en sentido amplio y defensa en sentido estricto ${ }^{15}$. La primera se corresponde con el uso casual del término "defensa" en el ámbito penal, entendida como cualquier gestión defensiva del imputado, incluyendo la coartada, la negación de culpabilidad, la negación de causalidad, la coacción, las inmunidades diplomáticas o ejecutivas, y la excepción de cosa juzgada. La segunda, en cambio, designa argumentos en que se reconoce que el delito fue cometido, excluyéndose por tanto los argumentos que niegan la comisión de este. Dentro de este último sentido, se encontrarían las justificaciones, las excusas (frente a "errores razonables"), las exculpaciones (e.g. incapaces) y las defensas no exculpatorias (como las inmunidades o la cosa juzgada ${ }^{16}$. En otro lugar, pero siguiendo la misma intuición, Gardner propone que es correcto distinguir casos de: 1) negación de haber cometido el delito (denial of wrongdoing); 2) aceptación de haber cometido el delito, pero contando con una justificación (justification); 3) aceptación de haber cometido el delito, sin tener una justificación, pero contando con una excusa (excuse $)^{17} ;$ y 4 ) negación de la responsabilidad propia (denial of responsibility $)^{18}$.

A partir de estas propuestas, en lo que sigue adoptaremos un concepto de defensa en sentido amplio: defensa es todo enunciado y todo elemento probatorio que le dé respaldo dirigido a oponerse, negar, cuestionar o introducir matices y modificaciones relevantes a aquello que se le atribuye a una de las partes en un proceso civil (demandante o demandado) o al imputado en un proceso penal a través de afirmaciones o acusaciones concretas. Una defensa bien podría consistir en invocar, en el proceso concreto, cualquiera de los cuatro casos identificados por Gardner. A su vez, los casos 2) y 3) no hacen más que dar cuenta de una excepción, en la terminología de Duarte d'Almeida, contemplada legalmente como causal de exculpación o justificación.

Un concepto como el propuesto pone el foco en los modos o razonamientos defensivos con relativa independencia a la posición procesal de las partes, siendo, por lo tanto, también predicable del demandante que quiera defenderse de afirmaciones del demandado o refutar prueba aportada por aquel. Así, el razonamiento defensivo consiste en el despliegue de defensas en distintas oportunidades y escenarios procesales.

\footnotetext{
15 GARDNER (2004).

16 Otros autores han clasificado las defensas en el proceso penal entre aquellas que invierten la carga de producción de prueba ("burden of production") y aquellas que invierten tanto la carga de producción de prueba como la carga de persuasión ("burden of persuasion"). A estas últimas se les denomina "affirmative defenses". Las defensas que se fundan en hechos exculpatorios, se argumenta, invierten la carga probatoria hacia el imputado o acusado. En este sentido, suelen definirse estas defensas como "circunstancias inusuales que, cuando son alegadas por la defensa, evidencian una situación en la que el propósito del derecho penal no se satisfaría con la condena del acusado". Jefreries y STEPHAN (1979) p. 1332, nota 13; y pp. 1334-1335. Sobre las nociones de "burden of production" y "burden of persuasion", véase MCNAUGHTON (1955) y FLETCHER (1968).

17 Una interesante distinción entre justificación y excusa en materia penal, una teoría de las excusas y una clasificación de ellas puede verse en MoOre (2010) pp. 482 y siguientes. Excusas legales son, para este autor, argumentos que el acusado puede presentar para derrotar muestras de responsabilidad prima facie.

18 GaRdner (2007) pp. 86-88. Un análisis más profundo de las tesis de Gardner nos llevaría a cuestiones de teoría del derecho penal que, interesantes como son, nos alejan del objetivo más modesto de este artículo. Otro esbozo de clasificación de las defensas, ahora en materia contractual, es la que propone HaRT (1949) pp. 175-176.
} 
Es posible emplear distintos criterios para clasificar las defensas que pueden invocarse en un proceso judicial. Un primer criterio, tradicionalmente usado por la dogmática procesal, es el tipo de regla que invoca quien se defiende, que puede ser de fondo o sustantiva, o de forma o adjetiva (que equivalen, aproximada y respectivamente a las excepciones perentorias y dilatorias en el proceso civil). Los hechos que constituyen estas excepciones requerirán de prueba y las disposiciones que las regulan pueden requerir de interpretación.

Un segundo criterio clasificatorio es el fin protegido a través del despliegue de la defensa: existen defensas "epistémicas" que tienen por objeto mejorar la información relevante para el proceso y contribuir, por esta vía, a la averiguación de la verdad, por ejemplo, la prueba de descargo; y existen defensas destinadas a proteger otros valores, bienes o intereses, pudiendo incluso afectar el fin epistémico del proceso, por ejemplo, la posibilidad de excluir prueba y la preclusión.

Un tercer criterio se refiere a la oportunidad procesal en que se articulan las defensas. El estadio natural para defenderse de las afirmaciones de la contraparte es ante el denominado "juez de fondo". Por ejemplo, con ocasión de la solicitud de una medida cautelar en contra del imputado, la defensa tiene la posibilidad de articular un razonamiento defensivo para evitar que sea decretada por el juez de garantía. En los alegatos de apertura y de clausura, el defensor se dedica, más que a rendir prueba, a presentar argumentos defensivos. No obstante, el razonamiento defensivo está especialmente presente en los mecanismos de impugnación ante el tribunal revisor, pero aquí lo que se "ataca" es la sentencia (aunque, de manera indirecta, pueden serlo las alegaciones de la contraparte). Excepcionalmente, además, existe razonamiento defensivo que permite incluso anular una sentencia firme y que se cristaliza en las causales de la acción de revisión.

Un cuarto criterio atiende al efecto que se persigue con la defensa, que puede ser, entre otros: a) hacer imposible la prosecución del proceso, de ser acogida (e.g. litispendencia, incompetencia del tribunal); b) subsanar tempranamente errores (e.g. ineptitud del libelo); c) reconocer un estado de cosas (e.g. prescripción); d) derrocar enunciados o hipótesis vertidos en el proceso (objetando el mal uso de una máxima de la experiencia o el recurso a una generalización espuria que no constituye una máxima); y, e) impugnar la aplicabilidad o interpretación de normas presentadas por la contraparte.

Para los efectos de este artículo conviene detenerse en las defensas probatorias, que son aquellas que específicamente tienen por objeto negar o modificar los enunciados fácticos vertidos en el proceso, o alegar nuevos "hechos" (e.g. circunstancias modificatorias de la responsabilidad, eximentes de responsabilidad, o extinción de la responsabilidad). La regla general es que los hechos sobre los que se funda la defensa deben probarse para que se produzca el efecto buscado de restar plausibilidad a los enunciados de la contraparte. Sin embargo, en un modelo procesal penal en el que la carga de la prueba recae sobre el órgano persecutor y en el que se presume la inocencia del imputado hasta que no se dé por probada su culpabilidad, la defensa podría permanecer pasiva en materia probatoria, simplemente negando los hechos de la acusación o instalando dudas sobre su culpabilidad. Por cierto, el defensor puede oponer una hipótesis defensiva incompatible con la acusatoria, caso en el cual requerirá probarla, como se verá más adelante. 
Al presentar defensas probatorias, las partes o intervinientes articulan razonamientos que toman la forma de inferencias y que conectan la información disponible. Una inferencia probatoria es un razonamiento que conecta la información disponible con la hipótesis fáctica o enunciado sobre hechos a probar mediante un enlace ${ }^{19}$. En sede judicial, la información disponible -denominada también "elementos de juicio", "pruebas" o "hechos probatorios"- es aquella que se aporta en el proceso. El enlace es una regla o enunciado general que correlaciona la hipótesis a probar con la información disponible.

Es precisamente la distinta naturaleza del enlace, al que se llama también garantía ${ }^{20}$, la que permite clasificar a las inferencias probatorias en epistemológicas, normativas e interpretativas, según el enlace sea empírico, normativo o conceptual respectivamente. En el primer caso, el enlace es una generalización que da cuenta de una regularidad empírica, y que puede formar parte del conocimiento común ("máxima de la experiencia") o del conocimiento científico. En el segundo caso, el enlace es una norma, sea una norma de presunción (legal o jurisprudencial) o una norma que asigne valor tasado a una prueba. En el tercer caso, el enlace es una regla conceptual o una definición (del legislador, de la dogmática o jurisprudencia, o de otro tipo). Estos enlaces presentan las siguientes estructuras: "Si se da el hecho 'p', entonces probablemente se dará el hecho 'q" (generalización empírica); "Si 'p', entonces debemos dar por probado 'q” (norma); “'p' cuenta como 'q'” (definición).

De acuerdo con este esquema, es posible que una defensa probatoria pueda estar destinada a objetar la credibilidad de los datos probatorios ${ }^{21}$, a desconocer la validez o solidez del enlace empleado por la contraparte o por el juez (i.e. regla de presunción, la máxima de la experiencia, conocimiento científico o concepto), a impugnar la suficiencia de los elementos probatorios para dar por probada una determinada hipótesis en vista al estándar de prueba aplicable, o a proveer nuevas inferencias para apoyar enunciados sobre hechos.

\section{EL ESCENARIO PROCESAL PENAL}

Como ya se ha sugerido, desde el punto de vista epistémico la prueba persigue la averiguación de la verdad. Esta finalidad está íntimamente conectada con la manera de justificar racionalmente las decisiones judiciales y, específicamente, con la forma de justificar externamente la premisa fáctica ${ }^{22}$. La verificación de la hipótesis en juego, y su calificación como una instancia de los hechos genéricos (clase de hechos) incluidos en el antecedente de la norma jurídica aplicable, son operaciones indispensables para que consideremos la decisión judicial como un auténtico ejercicio de jurisdicción: "el poder de determinar qué es lo que en derecho corresponde a cada uno”, a través de la aplicación de la ley (abstracta y general) a casos particulares y singulares ${ }^{23}$.

\footnotetext{
19 GonZález Lagier (2007).

20 Veáse, Toulmin (1958) tercer ensayo.

21 Véase Anderson, Schum y Twining (2015) pp. 98 y siguientes.

22 La clásica distinción entre justificación interna y externa es de WróbLEWSKI (1974).

23 Atria (2007) p. 37. Un desarrollo completo de esta noción en Atria (2016), en especial, pp. 150-154 y pp. 219 y siguientes.
} 
Junto con posibilitar la averiguación de la verdad como objetivo epistémico, las reglas procesales sirven a otros fines diversos, tales como la protección de un derecho fundamental o la necesidad de ir cerrando distintas etapas hasta obtener la clausura del proceso en un período determinado. Las reglas procesales que permiten excluir prueba y las que establecen plazos y oportunidades procesales se fundan en estos otros fines que también se tienen a la vista al diseñar cualquier proceso.

Como institución vertebral que da forma al conflicto, también las defensas sirven a distintos fines dentro del proceso. Así, la existencia de argumentos de defensa permite optimizar la información del juez a la hora de decidir el caso concreto y, al hacerlo, coadyuvan a la averiguación de la verdad. Las hipótesis alternativas presentadas por el defensor en favor del imputado y la existencia de prueba de descargo son argumentos defensivos que sirven a este fin epistémico, posibilitando una mejora de la calidad de la sentencia y evitando errores judiciales. La alegación de la nulidad procesal de una diligencia o la denuncia de haberse cometido infracciones a derechos fundamentales en la etapa de investigación (e.g. inviolabilidad del hogar), en cambio, sirven a otros fines, tales como velar por el cumplimiento de ciertas formalidades legales para dar validez a ciertos actos y proteger derechos fundamentales.

El razonamiento defensivo en el proceso penal tiene algunas características particulares que vienen dadas por los principios que lo estructuran y, en especial, por el principio de culpabilidad y la presunción de inocencia ${ }^{24}$. Solo debe sancionarse al culpable y a nadie más que al culpable. En caso de que no se supere el estándar de prueba de "más allá de toda duda razonable”, entonces el tribunal deberá absolver al imputado, quien seguirá considerándose inocente desde el punto de vista probatorio ${ }^{25}$.

El estatuto de inocente abarca no solamente una obligación de trato congruente con tal calidad durante el proceso, sino que también la exigencia de que debe ser probada su culpabilidad y superado el estándar de prueba "más allá de toda duda razonable", con lo que se desvirtúa la presunción ${ }^{26}$. Este escenario de alta exigencia probatoria y de distribución inequitativa del riesgo error (evitación de falsos positivos aún a riesgo de aumentar los falsos negativos) se explicaría, además de por el bien jurídico afectado por la imposición de una consecuencia jurídico-penal, por el carácter retributivo de la imposición de la pena en el proceso penal ${ }^{27}$.

Resulta también característico del proceso penal la manera en que se regula el "ámbito de la defensa”. El artículo 8 inciso 2 del CPP precisamente garantiza al imputado el

\footnotetext{
24 Sobre este último principio, la literatura es abundante. Véase, e.g., Fernández (2005), Ferrer (2010), VAlenZuela (2013), y GonZÁlez Lagier (2014).

25 La distinción y posibles combinaciones entre inocencia material, inocencia probatoria; culpabilidad material y culpabilidad probatoria; y culpable material e inocente las realiza, entre otros, LAUDAN (2005).

26 A esto se refiere la multidimensionalidad de la "presunción de inocencia" como regla de trato, regla de prueba y regla de juicio a la que se refieren los autores citados supra n. 28.

27 No se trata de un punto pacífico en la filosofía del derecho penal, sino de uno que cuenta con un largo debate a su haber entre prevencionistas y retribucionistas, del que no es posible hacerse cargo aquí. Sobre estos debates véase, entre nosotros, Mañalich (2007) y (2010). De todos modos, debemos remarcar que ese debate, desde el punto de vista de la definición del acto de imposición de la pena, tiene un carácter definido por el concreto merecimiento del autor del delito.
} 
derecho a formular los planteamientos y alegaciones que considerare oportunos, así como a intervenir en todas las actuaciones judiciales y en las demás etapas del procedimiento. Se trata de una noción de defensa en sentido amplio que incluye el derecho a la defensa técnica y material, también respaldada por normativa internacional ${ }^{28}$.

Como se ha sugerido, el proceso penal puede ser descrito como un "rito contra la incertidumbre" al estructurarse en torno a dos extremos en tensión: ser responsable o no ser responsable, o entre inocencia y culpabilidad. El juez debe decidir, con toda la información vertida en el proceso y en este escenario de dudas, acerca de la verdad o falsedad de la hipótesis acusatoria. Tanto la sentencia condenatoria como la absolutoria disuelven esta incertidumbre: o bien se es culpable o bien se es inocente.

Desde el punto de vista del razonamiento probatorio, la sentencia de un proceso penal puede adoptar las formas siguientes: a) "está probado que 'p"; b) "no está probado que 'p"”; c) "está probado que no 'p", siendo "p" la hipótesis de la acusación. Para llegar a cualquiera de estas conclusiones respecto de la premisa fáctica se requiere valorar la prueba rendida y determinar si se ha satisfecho o no el estándar de prueba que corresponda.

En el primer caso ("está probado que 'p"), esa premisa de hecho es el resultado de haberse valorado racionalmente la prueba y haberse comprobado que se ha superado el estándar de prueba respecto de "p". Lo que quiere decir que, si se intentó desplegar alguna clase de defensa probatoria, estas fracasaron.

En el segundo caso ("no está probado que 'p"), la premisa fáctica es el resultado de haberse valorado racionalmente la prueba y haberse comprobado que no se ha superado el estándar probatorio. Que no se haya alcanzado el umbral de suficiencia probatoria puede deberse a consideraciones distintas que podrían o no concurrir de manera conjunta. Por una parte, si se desplegaron defensas probatorias y la o las hipótesis defensivas no fueron refutadas, entonces ello podría explicar aquella conclusión en tanto persistirían dudas razonables acerca de la culpabilidad del acusado. En este caso, no se requiere que se tengan por probadas las hipótesis defensivas. Por otra parte, es posible que la prueba de cargo simplemente se considere débil e insuficiente, en su conjunto, para dar por acreditado el hecho y/o la participación del acusado ${ }^{29}$.

En el tercer caso ("está probado que no 'p'”) se ha probado una hipótesis defensiva que resulta total o parcialmente incompatible con la existencia de "p", impidiendo la condena. En este caso, no se trata de probar la falsedad o insuficiencia probatoria de " $p$ ", sino de comprobar la verdad de la hipótesis alternativa ${ }^{30}$. En concreto, la incompatibilidad total puede conducir a: (a) la prueba de la concurrencia de elementos que conduzcan a la exculpación del acusado o a la justificación de la conducta; o (b) la prueba que demuestre la imposibilidad física de la hipótesis acusatoria. En cambio, la incompatibilidad parcial consiste en probar hipótesis de hecho que conduzcan a una morigeración de las consecuencias ju-

\footnotetext{
${ }^{28}$ Véase supra n. 8. Sobre la relevancia del derecho a la defensa del imputado, véase Horvitz y López (2002) pp. 76 y ss., y GARDNER (2007).

29 ACCatino (2011) pp. 484-489.

30 FERrer (2005) pp. 79-101.
} 
rídicas pretendidas por la acusación, o bien a un nuevo escenario probatorio, por ejemplo, por recalificación y redefinición de la hipótesis acusadora.

En este tercer caso, ¿cuál debiese ser la regla de estándar probatorio para evaluar la suficiencia probatoria de una hipótesis de hecho alternativa incompatible con la acusatoria? Dicho de otra manera, ¿cuáles son las condiciones que permiten dar por probada esta hipótesis de hecho defensiva y que justifican una sentencia absolutoria, o bien un cambio en el escenario probatorio que impide una sentencia condenatoria? En estas, que pudiéramos llamar defensas para probar la inocencia, quisiéramos concentrarnos. El proceso penal no requiere que el defensor pruebe la inocencia, sino que esta es una facultad de la defensa ante el tribunal de juicio oral en lo penal, o ante el juez revisor que conozca de un recurso de nulidad o de la acción de revisión. En este último caso, hay una hipótesis específica que se funda en la prueba de la inocencia de un condenado por sentencia firme.

\section{LA ACCIÓN DE REVISIÓN}

Los mecanismos de impugnación son medios para cuestionar la corrección de una resolución judicial, alegando la existencia de errores o abusos en su dictación, con el objetivo de lograr que se subsane el error, se purgue el vicio, se corrija la falta o abuso grave, o se anule o revoque la decisión injusta. Especial relevancia adquieren los mecanismos de impugnación en contra de sentencias definitivas, es decir, de aquellas que ponen fin a un proceso resolviendo la cuestión o asunto controvertido ${ }^{31}$.

La interposición de un recurso judicial supone explicitar un razonamiento impugnatorio, es decir, requiere articular las razones que respaldan la solicitud de examen de la decisión judicial respectiva. Este razonamiento impugnatorio es intrínsecamente defensivo y consiste, en la mayoría de los casos, en la denuncia de tipos de errores cometidos por el juez o tribunal durante la tramitación del proceso o en la dictación de la sentencia, y que se encuentran expresados como causales o criterios legales de impugnación, sean éstos genéricos o específicos. Ejemplos de estas causales en el ámbito del proceso penal son que haya existido una vulneración a los derechos fundamentales, una errónea aplicación del derecho que hubiere influido sustancialmente en lo dispositivo del fallo, la ausencia del defensor en alguna de las oportunidades procesales exigidas por el legislador, o que el juez no haya valorado toda la prueba rendida o que dicha valoración no permita la reproducción del razonamiento utilizado para alcanzar las conclusiones fácticas a las que se llega ${ }^{32}$.

La acción de revisión constituye un mecanismo de impugnación extraordinario que permite revocar sentencias firmes en los casos contemplados por el legislador ${ }^{33}$. En materia

\footnotetext{
31 CPC, artículo 158.

32 CPP, artículos 473 y 474.

33 Sobre la acción de revisión, véase clara descripción que realiza CALAMANDREI (2019). En el ámbito nacional, existe un trabajo monográfico de la revisión penal de PAillas (2001), además del tratamiento en los manuales de recursos procesales. Por todos, Maturana, y Mosquera (2018) capítulo XIII. Una reciente investigación que examina las sentencias de la Corte Suprema en el período 2007-2017 y critica la práctica judicial como desconocedora de un "modelo adversarial de revisión” es la de FERnÁNdez, y OlavarRía (2018). Quien mejor ha estudiado la revisión y el caso de condena de inocentes en Chile es DucE (2015a), (2015b), y (2017).
} 
procesal penal se puede solicitar la revisión de sentencias condenatorias firmes en cualquier momento (i.e. es imprescriptible), argumentándose que concurren los elementos de una o más de las causales del artículo 473 del CPP. Algunas de las hipótesis son casos de errores (sean ellos excusables o no), mientras que otras hipótesis son casos de abusos o faltas graves (claramente lo es el supuesto de prevaricación contenido en la letra e)). Todas las causales se fundan en una "valoración asimétrica del riesgo de injusticia del resultado del proceso" penal, que valora "como más grave el riesgo de un "falso positivo"34. Este mismo principio de valoración asimétrica, pero referida al riesgo de una decisión errónea no firme, es el que tiene en cuenta el legislador procesal penal para la fijación de un estándar de prueba exigente para la sentencia condenatoria ${ }^{35}$.

En lo que sigue, analizaremos la causal que se funda en la demostración de la inocencia del condenado. El CPP prescribe que podrán revisarse sentencias condenatorias firmes cuando "con posterioridad a la sentencia condenatoria, ocurriere o se descubriere algún hecho o apareciere algún documento desconocido durante el proceso, que fuere de tal naturaleza que bastare para establecer la inocencia del condenado"36.

Tal como se ha señalado, este es un caso de injusticia sustantiva que se funda en la falsedad de la premisa fáctica de la sentencia condenatoria, que en el caso concreto resulta de la demostración positiva de la inocencia del condenado ${ }^{37}$. El razonamiento defensivo de quien acciona se despliega, entonces, presentando defensas probatorias que demuestren la inocencia del condenado. La finalidad de esta acción es precisamente modificar la atribución de responsabilidad de una sentencia que ya goza de autoridad de cosa juzgada y de la que se denuncia haber cometido un error material consistente en la condena de un inocente $^{38}$. Desde el punto de vista de la manera en que la causal se encuentra regulada, puede colegirse que se trata de un error material que solo se ha podido apreciar sobrevinientemente. En efecto, esta hipótesis nada dice acerca de si, al momento de dictarse la decisión, se cometieron o no errores inferenciales. Desde el punto de vista de la sentencia que acoge la revisión, se realiza un juicio retrospectivo acerca de la sentencia impugnada que afirma la falsedad de la premisa fáctica en la que aquella se fundó, reconociendo que ahora existe más y/o mejor información disponible que la existente al dictarse la sentencia impugnada.

Ahora bien, hay dos cuestiones que resultan relevantes con relación a esta causal. En primer lugar, qué se entiende por "hechos o documentos desconocidos durante el proceso". Y, en segundo lugar, cuál es el estándar de prueba aplicable a la hipótesis de inocencia.

Hechos o documentos desconocidos durante el proceso son aquellos que no forman parte del expediente judicial, o no integran el acervo probatorio que ha podido tener a la vista el tribunal o no han servido de base para la formación de la convicción del tribunal ${ }^{39}$.

\footnotetext{
MaÑalich (2020).

35 Código Procesal Penal, artículo 340.

36 Código Procesal Penal, artículo 473 letra d).

37 Mañalich (2020).

38 Ferrer (2018) pp. 419-420.

39 Mañalich (2020) pp. 40-41.
} 
Con relación a la segunda cuestión, y pese a que la tentación sería hacer aplicable el estándar de "más allá de toda duda razonable", ello debe ser descartado, toda vez que esta alta exigencia probatoria está diseñada para la hipótesis acusatoria y expresa la necesidad de evitación de la condena de inocentes.

La verificación de las hipótesis de hecho de las defensas debe seguir, en algún sentido, esa preferencia general del sistema, contando con una regla de baja exigencia probatoria para la inocencia que resulte compatible con la evitación de la condena del inocente. Así, la inocencia debe situarse en un escenario probatorio que mantenga su posición de ventaja frente a la prueba de la hipótesis acusadora. Con lo dicho, podría inferirse que la regla debiese ser la de preponderancia de la evidencia en tanto regla probatoria mínima, estándar supletorio ${ }^{40}$ o regla de defecto ("statu quo" en la terminología de Letelier) ${ }^{41}$. El estándar de probabilidad prevaleciente es, por lo demás, un estándar que evita en general el error en tanto lo distribuye de manera simétrica entre las partes y que se aplica a falta de razones para valorar de manera más negativa un falso negativo que un falso positivo. Por ello, pareciese ser el apropiado para dar por probada la verdad de la hipótesis de inocencia.

Sin embargo, deberíamos incluir otra dimensión en la discusión sobre el estándar de prueba de la inocencia. Suele sostenerse en el contexto de estándares poco exigentes, que la hipótesis de hecho debe ser tendiente a la completitud o la integridad. Es decir, debe ser capaz de clausurar, en gran medida, el hallazgo de nuevos datos que modifiquen el estado de cosas definido por la inocencia. Una hipótesis comparativamente mejor que otra puede ser, en términos de su peso y apoyo en las evidencias, todavía una mala tesis. La noción de completitud se incorpora, precisamente, como una manera de evitar esta posible objeción.

En el contexto de la acción de revisión, sin embargo, se podría renunciar a la exigencia de completitud: si los avales probatorios de la inocencia son suficientes para la derrota de la tesis de culpabilidad contenida en la sentencia, y si es clara la necesidad de evitar la condena de inocentes, aquella exigencia es excesiva. Precisamente, el sentido de la revisión es canalizar un argumento defensivo de cara a la afirmación de una mejor información probatoria que aquella que ha sido tenida en cuenta para condenar. Esto supone considerar la acción de revisión como un mecanismo impugnatorio que formula un juicio relativo a la disponibilidad de una mejor explicación del caso que conduce a la afirmación de inocencia del acusado.

\section{LA CORTE SUPREMA Y LOS HECHOS NUEVOS}

Llegados a este punto, vale la pena preguntarse cómo se ha comportado la Corte Suprema chilena respecto de la hipótesis de la letra d) del artículo 473 antes citado. Si miramos los casos de revisión de los últimos ocho años, podremos advertir algunos hallazgos de interés. El principal es que la falta de definición relativa a la exigencia probatoria que debe alcanzarse para la verificación de una hipótesis defensiva genera vaivenes en el razonamiento de la Corte e intentos por invocar un alto estándar de suficiencia probatoria.

\footnotetext{
40 Accatino (2011) p. 487.

41 Letelier (2018). En el mismo sentido, Mañalich (2020) p. 43.
} 
Como veremos, la falta de definición del estándar probatorio impacta ciertamente en un punto central en el marco de la decisión probatoria relativa a la inocencia en el contexto del conocimiento de la revisión penal ${ }^{42}$.

Una aproximación general a la acción de revisión en Chile, que también ha abordado algunos problemas probatorios, es la elaborada por Duce. Sin perjuicio del completo panorama de la revisión que realiza, no se detiene en las debilidades y efectos que generan los argumentos a través de los cuales se justifica la concesión de las revisiones, sino que más bien se concentra en el problema general de la justificación de condenas de inocentes que se develan en dicha práctica ${ }^{43}$.

Como se indicó con anterioridad, nos hemos centrado exclusivamente en las sentencias que acogen la acción por la vía de la letra d) del artículo 473 CPP. Su análisis consistió en detectar razonamientos recurrentes a la hora de considerar que existe un "hecho nuevo" como prueba de la inocencia. En el contexto de reconocimiento de la inocencia a través de la verificación de un "hecho nuevo" y sus correlativas exigencias, se torna crucial la pregunta sobre las defensas probatorias. En este sentido, se trata de un aspecto más acotado que los trabajos del Duce ya citados, pero muestra un rasgo que resulta llamativo en la manera de conceder la revisión por esta causal en el sistema judicial chileno.

Un segundo hallazgo es que la prueba de la inocencia en el contexto de la acción de revisión suele hacerse a través de "información pericial", la cual, además, es considerada como prueba suficiente para dar por verificada la hipótesis de la inocencia.

La Corte Suprema suele considerar que, para revisar una sentencia por existir un hecho nuevo que permite establecer la inocencia, necesita tener a la vista una prueba de alto valor y suele asociar esta necesidad a la presencia de prueba pericial. En el periodo de funcionamiento del sistema procesal penal inaugurado el año 2000, es altamente recurrente aplicar esta etiqueta de prueba "de alto valor o fiabilidad" para la información producida por expertos, que, sin embargo, perfectamente podrían ser considerados simples documentos o testimonios ${ }^{44}$.

Ahora bien, si la pregunta es qué es lo que ha entendido la Corte Suprema por "información suficiente" para acreditar la inocencia, veremos que la prueba pericial surge como la respuesta natural o intuitiva para este fin. En este punto, es conveniente adelantar que dicha consideración es equivocada, y que seguramente proviene del alto valor que suele asignársele a la prueba pericial por los intervinientes y jueces en el contexto del proceso penal.

\footnotetext{
42 Si este es el problema fundamental, no es el único. Hemos querido dar cuenta también de ciertos rasgos en la búsqueda de suficiencia probatoria realizada por la Corte. Esto la ha llevado al campo de la sobrevaloración de la prueba pericial, aunque es claro, no se trata de una consecuencia que pueda derivarse solamente de esta vaguedad en la conceptualización del estándar de prueba.

43 Véase, especialmente, Duce (2015a, 2015b y 2017). Un punto muy relevante de estos estudios es que muestran que todas las acciones de revisión acogidas lo son por la causal del artículo 473 letra d) y que el 68,7\% de las revisiones acogidas son presentadas por el Ministerio Público. DucE (2017) p. 34.

44 Existe una amplia literatura que discurre sobre el problema de sobrevaloración epistémica y semántica de la prueba científica. Véase Gascón (2013), Taruffo (2010), Vázquez (2015) y Duce (2018).
} 
La siguiente tabla ${ }^{45}$ da cuenta de las acciones que terminaron con sentencias que acogen la revisión por la causal del artículo 473 letra d):

\begin{tabular}{|c|c|c|c|c|c|c|c|c|c|c|}
\hline Año & 2012 & 2013 & 2014 & 2015 & 2016 & 2017 & 2018 & 2019 & 2020 & Total \\
\hline $\mathrm{N}^{\circ}$ Casos & 9 & 4 & 2 & 1 & 1 & 3 & 1 & 4 & 1 & 26 \\
\hline
\end{tabular}

Una cuestión llamativa es la falta de pronunciamiento por parte de la Corte Suprema chilena sobre el grado de corroboración que debe alcanzar una hipótesis defensiva como lo es aquella que consiste en afirmar que existe un hecho nuevo que, por su naturaleza, basta para acreditar la inocencia del condenado. Así, ninguna sentencia concibe la exigencia probatoria de la inocencia de un modo autónomo. Al contrario, es recurrente la cita a la disposición del artículo 340 del CPP para sostener que la prueba que es tenida en cuenta para respaldar la acción muestra que ese estándar no se encontraría cumplido.

Sin embargo, esa mención es insuficiente de cara a la comprensión de la prueba de la inocencia, pues esconde una comparación hipotética entre la noción de falta de culpabilidad y la verificación de una hipótesis de hecho compatible con la inocencia. El caso más recurrente es el de la suplantación: la Corte Suprema suele revisar sentencias condenatorias a solicitud del Ministerio Público y en las cuales existe un error en la persona, y por tanto la condena producida en contra de un sujeto no se justifica, simplemente, porque ese sujeto no realizó los hechos.

Así, la indefinición de la suficiencia probatoria parece poner a la Corte en situación de buscar alguna indicación o coordenada con lo que pudiera enfrentar la decisión sobre prueba de la inocencia asumiendo la satisfacción, previa, del estándar de prueba de duda razonable. Esta búsqueda por parte de la Corte parece haberse dirigido al campo de los medios de prueba y su valor. En particular, pareciera razonarse recurriéndose a un medio probatorio que tenga asociado algún juicio general sobre alto valor.

Por ello, junto a la ausencia completa de digresiones sobre la prueba de la inocencia en términos de suficiencia general, se suelen fundamentar las sentencias que conceden las revisiones en información que tenga el carácter de "científica" o pericial. De hecho, en los últimos dos años, en todos los fallos se menciona un informe pericial para constituir las "probanzas" a partir de las cuales se fundamenta la decisión de la sentencia.

Como panorama general, existen tres clases de fenómenos que aparecen en la práctica jurisprudencial de la Corte Suprema: a) el conocimiento científico está fuertemente mediado; b) se asume que la pericia es capaz de definir una hipótesis defensiva; y c) la concurrencia de la pericia oculta una investigación defectuosa.

\section{Alta mediación}

El proceso penal está diseñado con la consideración importante del denominado principio de inmediación. Sin embargo, en el caso de la revisión, la prueba que da lugar a

45 Se utilizó como criterio de clasificación el año de la dictación de la sentencia que resuelve la revisión respectiva. 
la acción basándose en la causal contenida en la letra d) del artículo 473 CPP se caracteriza por una alta mediación.

La Corte Suprema suele aceptar como suficiente la concurrencia de una prueba de cargo que da por probado un caso de suplantación, si logra establecer que se encuentra "científicamente establecido" que un supuesto de la prueba de la revisión ha quedado fijado. En algún sentido, se considera que la prueba de la acusación por suplantación que supera la regla de la duda razonable respecto de una persona es un dato suficiente para dar por acreditada la inocencia de otro que sufre condena por quien lo ha suplantado.

Así, la Corte Suprema ha afirmado, por ejemplo: "Aduce que de lo anterior se tomó conocimiento por la denuncia efectuada por Marcelino Harry Cárdenas Ramos el 28 de junio de 2011 ante la Fiscalía Local de Pudahuel, lo que dio origen a la investigación RUC $\mathrm{N}^{\circ}$ 1100650146-1, donde resultó condenado Robin Tibor Godo Ramos como autor del delito de usurpación de nombre, a sesenta y un días de presidio menor en su grado mínimo, luego de comprobar que fue él la persona que realmente cometió el delito a que se refiere el fallo recaído en la causa RUC No 1100354232-9, decisión que se apoyó principalmente en el Informe Pericial Caligráfico No 1685, del Laboratorio de Criminalística de la Policía de Investigaciones, que comparó la firma estampada en el Acta de Información de Derechos al Detenido y Apercibimiento del artículo 26 del Código Procesal Penal, de 28 de julio de 2009, con la escritura y firma genuina de Robin Tibor Godo Ramos, cuyo resultado indicó la correspondencia entre éstas, luego de la comparación con la escritura y firma genuina de Marcelino Harry Cárdenas Ramos" ${ }^{46}$.

Este escenario le permite a la Corte Suprema considerar que concurre una prueba pericial para dar por acreditada la inocencia de quien ha denunciado la suplantación. Sin embargo, esta argumentación no explica por qué esa prueba es capaz de justificar la veracidad de la tesis defensiva, es decir, de la inocencia del condenado, ante una regla de suficiencia probatoria.

Esta práctica de alta mediación no sería problemática per se, sino que el defecto de fundamentación proviene de la ausencia de pronunciamiento sobre las credenciales científicas de su fuente de información en casi todos los casos en que la Corte Suprema se ha basado en pericias para dar por establecida la inocencia del acusado. Así, por ejemplo, el año 2012 sostuvo que "se realizó un informe pericial de comparación de rostro No 1309-2011 de fecha 6 de diciembre del mismo año, realizado por la Policía de Investigaciones de Chile y en la hoja de ruta de Gendarmería de Chile de 16 de marzo del mismo año, concluyendo que dicha fotografía corresponde en realidad al rostro de Robin Tibor Godo Ramos, C.I. No 14.909.754-6.2" 47 .

La existencia de ese informe de "comparación de rostros" y la denuncia por suplantación hecha por un tercero constituyen para la Corte:

46 FISCAL REGIONAL DE LA ZONA METROPOLITANA CENTRO NORTE CON 7 JUZGADO DE GARANTÍA DE SANTIAGO (2012). El destacado es de la sentencia, al igual que en los extractos que luego se transcriben en el texto principal.

47 FISCAL REGIONAL DE LA ZONA METROPOLITANA OCCIDENTE CON 1 JUZGADO DE GARANTIAA DE SANTIAGO (2012). 
"hechos nuevos, desconocidos durante el pleito, que se descubrieron con posterioridad al pronunciamiento condenatorio, medios todos que son bastantes para comprobar la inocencia de Marcelino Harry Cárdenas Ramos”" ${ }^{38}$.

Esta estructura aparece constantemente repetida en las decisiones de la Corte en cuestión: se duda de la existencia de un dato condenatorio y se asume que debe tenerse en cuenta el carácter pericial o "científico" de una evidencia, que se considera capaz de entregar datos que justifiquen la inocencia del condenado. Un tal razonamiento es, cuanto menos, dudoso.

La falta de avales acerca de la cientificidad de las pruebas permitiría que, en realidad, cualquier clase de medio probatorio pueda, por el solo hecho de haber sido calificado de pericial o científico, ser capaz de corroborar una hipótesis de hecho que justifique la absolución del acusado.

Parece claro que debiera avanzarse hacia una práctica en la que se dé cuenta de todos los datos que permiten realizar las inferencias probatorias que conducen, por ejemplo, a la absolución en el marco de la revisión, mostrando que la prueba de la acusación en un caso es derrotada por la prueba de una hipótesis alternativa en otro, aunque se haya producido ya la condena.

La conclusión ahora más evidente es que la Corte Suprema no necesita como condición sine qua non de "pruebas científicas" para dar por acreditada la hipótesis de hecho que justifica la revisión, sino que cualquier medio probatorio puede ser suficiente si es capaz de probar la hipótesis de hecho de la inocencia.

\section{PeRICIA E HIPÓTESIS DEFENSIVA}

Por otra parte, la Corte Suprema considera que la pericia que tiene en cuenta como fundamento de la revisión es capaz de dar por establecida, es decir, que puede probar, una hipótesis defensiva. Esta es, también, una forma de razonar que se reitera en las sentencias revisadas, y que puede ser ilustrada con el siguiente pasaje:

"en el caso se ha producido la situación que regla el artículo 473 letra d) del Código Procesal Penal, toda vez que con posterioridad a la fecha de la sentencia se descubrió que la persona que fue detenida y puesta a disposición del tribunal, no correspondía efectivamente a Pontigo Peña, sino que era un sujeto distinto de aquél que usurpó su identidad, persona que no ha podido ser identificada, pero existiendo certeza absoluta de que no fue quien resultó condenado, lo que se pudo establecer a través de una prueba pericial caligráfica respecto de la firma estampada por el detenido en el Acta de Intimación de Orden de detención Verbal, además de un peritaje de voz con el material recopilado en la audiencia respectiva" ${ }^{39}$.

Conforme a esta sentencia, la pericia que dio lugar a la prueba de la suplantación es capaz de producir "certeza absoluta" de la hipótesis de hecho que debe probarse. En ningún

\footnotetext{
${ }^{48}$ Considerando cuarto, FISCAL REGIONAL DE LA ZONA METROPOLITANA OCCIDENTE CON 1 JUZGADO DE GARANTÍA DE SANTIAGO (2012).

49 FISCAL REGIONAL DE LA ZONA METROPOLITANA CENTRO NORTE CON 6 JUZGADO DE GARANTÍA DE SANTIAGO (2012).
} 
momento la Corte Suprema se detiene a definir qué significa esta certeza absoluta, pero pareciera que se refiere a la relación entre lo establecido en ambas sentencias.

Como se ha condenado a alguien en un proceso, y esa condena se opone en términos de coherencia con la sentencia anterior, entonces procede absolver a uno de los sujetos. La absolución respecto del caso en que se ha producido la condena descansa en la prueba de una hipótesis defensiva, que ahora toma la forma de la prueba de una hipótesis alternativa incompatible con la hipótesis acusatoria probada y que condujo a la condena. Pero esto aparece como un exceso de exigencia para la hipótesis defensiva.

No parece razonable que la hipótesis alternativa de la defensa deba probarse hasta satisfacer la duda razonable en otro procedimiento. Lo que es más llamativo es que, aunque esto se produzca, la Corte Suprema no se pronuncia otra vez sobre la concurrencia de esa hipótesis y su prueba en concreto. La asocia a una pericia y con eso tendríamos "certeza absoluta".

Por cierto, dicho razonamiento es extremadamente llamativo. Por un parte, la confusión entre el plano de la falta de justificación de la hipótesis de la sentencia y la de la acción de revisión impide enfrentar el problema del establecimiento de una regla o noción acerca de la suficiencia de los datos que justifiquen una revisión. Por otra parte, la idea de certeza en tanto ideal inalcanzable, esconde una desproporcionada exigencia de revisión. Como veíamos anteriormente, la prueba de la inocencia en tanto hipótesis defensiva es tributaria de la distribución del error en términos de evitación de la condena de inocentes. Por ello, la prueba de la inocencia no debe dirigirse, en realidad, a superar altos niveles de exigencia probatoria, pues de este modo tendríamos que el sistema exige lo mismo para la prueba de la inocencia en este nivel de revisión de sentencias firmes, como respecto de la culpabilidad en la sentencia.

\section{PERICIA E INVESTIGACIÓN}

Con un tratamiento como el descrito parece ocultarse un dato muy relevante para el proceso penal: la acción de revisión muestra un despliegue defectuoso de la investigación y no se está produciendo en esta sede una sofisticación de criterios probatorios, como sin embargo pudiera esperarse.

Existen casos donde se ha condenado a personas, por ejemplo, por conducir con licencia falsa, siendo ésta verdadera. La definición de la autenticidad de esa licencia pasa por un "informe pericial documental". Así, la Corte ha sostenido:

"con posterioridad a los hechos y al fallo condenatorio se realizó un informe pericial documental por el Departamento de Criminalística de Carabineros de Chile a la licencia que portaba el sentenciado el día de su detención, signado con el No 2564-2013, el que concluyó que el documento es original" 50 .

Pero esta consideración, pareciera, debió ser tenida en cuenta durante el proceso de condena. Y ello porque una parte del supuesto de hecho sustentado por una acusación de uso de un documento falso pasa por definir si el documento es, efectivamente, falso.

Así aparece repetido invariablemente en las sentencias consultadas: toda revisión por hecho nuevo parece entrañar la prueba de un hecho particularmente relevante de la hipó-

50 DEFENSORÍA PENAL PÚBLICA CON 7 JUZGADO DE GARANTÍA DE SANTIAGO (2013). 
tesis acusadora. La Corte Suprema ha dado lugar a la revisión cuando aprecia que el cuadro probatorio de la condena aparece claramente afectado en términos de probar una hipótesis alternativa. Así ocurre cuando se realiza un informe caligráfico para definir si la persona sometida al proceso es o no quien dice ser, caso paradigmático de revisión en los últimos años. En todos ellos parece que el diagnóstico es que existen investigaciones de baja calidad y un apresuramiento en la condena.

Pero la letra de la ley no parece comprender una práctica como ésta. Antes bien, el legislador diseñó un sistema de revisión de sentencias y por tanto de decisiones finales del proceso penal. Es claro que los errores que se cometen durante la etapa de investigación redundan y contribuyen a producir errores en la sentencia, pero si la revisión solo es capaz de expresar esta dimensión, se transforma en un mecanismo corrector de errores procedimentales, alejándose de su configuración de recurso extraordinario para subsanar injusticias graves. El asunto es que, sobre todo en el contexto de la letra d) del artículo 473 del CPP, esta herramienta debería dar luces sobre el significado de las condiciones para probar la inocencia y, por tanto, también debería servir de referencia para la comprensión de las condiciones para condenar.

\section{CONCLUSIONES}

La aproximación tradicional que asocia la noción de defensa a la de "excepciones" en el proceso es, como se sugirió en lo precedente, excesivamente reduccionista. En primer lugar, porque implica asumir una clasificación binaria de los argumentos defensivos como si se tratara simplemente de afirmar la correlación entre acciones y pretensiones, por una parte, y las excepciones como modos de defensa, por otra. En segundo lugar, porque se atribuye aquel ejercicio defensivo al demandado, como una actividad centrada exclusivamente en la parte. Esto es insuficiente para dar cuenta de la importancia que el razonamiento defensivo tiene en las distintas etapas de un proceso judicial y en los mecanismos de impugnación de la decisión del juez o tribunal que resuelve la controversia. En alguna medida el tribunal se enfrenta a la necesidad de razonar desde el punto de vista defensivo sin que ese ejercicio se agote en la parte que debe exponer este punto de vista ante una determinada pretensión procesal.

En este trabajo se ha perseguido oponer a la aproximación tradicional una concepción más amplia y con mayor capacidad explicativa, bajo el supuesto que puede ser un punto de partida para construir una taxonomía de las defensas comprensiva de distintos tipos de procesos y etapas procesales. Asimismo, una conceptualización de defensa sensible a estos factores permite reconducir diversas causales de impugnación a la categoría de defensas probatorias. Ello, a su vez, es necesario, por una parte, para determinar cuáles son sus condiciones de corrección, y, por otra parte, para analizar críticamente cómo se emplean en la argumentación judicial. Una práctica judicial dotada de un claro aparato conceptual eleva la calidad de sus decisiones.

El escenario recursivo en general es particularmente pertinente para realizar dichos objetivos y, la acción de revisión en el ámbito penal es el punto más preclaro del sistema jurídico a este respecto, como hemos intentado mostrar. En el ámbito penal, el dilema del 
castigo del inocente -que se ha visto impactado por la concepción más común del principio de presunción de inocencia y del principio de culpabilidad en las reglas procesales y sustantivas- condiciona la producción de elementos probatorios por parte de los intervinientes y la valoración de la decisión probatoria del juez o tribunal penal. Tal es así que la decisión política de contar con un estándar de alta exigencia probatoria se funda, como se sabe, en evitar al máximo los falsos positivos sin por ello paralizar la persecución penal estatal.

En este contexto procesal, la carga de producir prueba suficiente recae en la acusación y, por ende, la defensa no está obligada, en principio, a aportar más prueba que aquella necesaria para desvirtuar la hipótesis acusatoria o para generar dudas razonables sobre la culpabilidad. Sin embargo, en ciertos casos, la defensa articula hipótesis defensivas que suponen (durante el juicio oral) o requieren (por ejemplo, al accionar de revisión) la prueba de la inocencia. Una tal inversión del escenario probatorio hace que el fundamento de un estándar de prueba diseñado para la decisión de culpabilidad no sea aplicable a un estándar de prueba para la decisión de inocencia.

La causal de revisión que requiere demostrar la inocencia del que ha sido condenado por sentencia firme a través de hechos o documentos ocurridos o conocidos con posterioridad a su dictación nos enfrenta, así, a la necesidad de fundamentar un estándar de prueba para la inocencia. Igualmente, exige una reflexión detenida de lo que significa hecho o documento nuevo y de los criterios para, en casos concretos, darles fuerza probatoria. Sin embargo, en las sentencias en las que la Corte Suprema chilena ha acogido la acción de revisión por la causal del artículo 473 letra d), no se aprecia la existencia de un ejercicio de valoración de la prueba que determine el grado de confirmación de la hipótesis de acuerdo con criterios de solidez epistémica, ni que permita afirmar que aquel grado de confirmación de la hipótesis sea suficiente para superar el umbral probatorio exigido ${ }^{51}$.

La Corte Suprema se ampara fuertemente en la denominada "prueba pericial" o científica para corregir los errores materiales de sentencias condenatorias, asumiendo que cuenta con fiabilidad reforzada respecto a otros medios probatorios, sin que se ofrezcan mayores razones sobre esta intuición. No hay indicación respecto de la manera de delimitar entre buena y mala ciencia ni sobre las tasas de error de estas conclusiones expertas. Menos se ha detenido en describir la relación entre prueba y decisión o en determinar el estándar de prueba a aplicar a la hipótesis defensiva. El uso de prueba pericial produce la paradoja de que es usada confiando en su "cientificidad" u "objetividad" cuando la evidencia demuestra que su uso incorrecto, en realidad, aumenta la probabilidad de errores judiciales ${ }^{52}$.

La principal conclusión que ofrecemos es que urge el desarrollo a nivel doctrinario y luego jurisprudencial de una noción de estándar de prueba para la inocencia que fije una exigencia probatoria de probabilidad prevaleciente. Una noción de este tipo permitiría, en particular, dar cuenta del tipo de decisión y, por lo tanto, del tipo de error que la Corte Suprema enfrenta en el preciso campo de la acción de revisión estudiada. Además, permitiría

\footnotetext{
51 Sobre estos criterios, vid. González Lagier (2020) pp. 83-84.

52 Duce (2018) p. 254. Aunque el estudio se ocupa del error en las sentencias condenatorias firmes, nada impide extender estas conclusiones a la sede de revisión de aquellas sentencias y alertar sobre los peligros del uso incorrecto de la prueba pericial también en el momento de "corregir sentencias erróneas".
} 
dar una coordenada importante acerca de la prueba de la inocencia en el proceso penal en general. En este segundo sentido, dicha noción daría luces en el contexto del juicio oral acerca de las condiciones probatorias a las que se enfrenta la prueba de la hipótesis alternativa defensiva que resulta incompatible con la hipótesis acusadora. Todo esto muestra que no es irrelevante cuál es la noción de defensa que se asuma y, por lo tanto, la importancia de considerar la aquí propuesta.

\section{BIBLIOGRAFÍA CITADA}

Accatino, Daniela (2011): "Certezas, dudas y propuestas en torno al estándar de la prueba penal”, Revista de Derecho de la Pontificia Universidad Católica de Valparaiso, vol. XXXVII: pp. 483-511.

Anderson, Terence, Schum, David y Twining, William (2015): Análisis de la prueba (Madrid, Marcial Pons).

Atria, Fernando (2007): "La improbabilidad de la jurisdicción", en Couso, Javier, y ATRIA, Fernando (ed.) La judicatura como organización (Santiago, Expansiva).

Atria, Fernando (2016): La forma del derecho (Madrid, Marcial Pons).

Benabentos, Omar (1998): Excepciones y defensas procesales (Rosario, Juris).

Calamandrei, Piero (2019): "Revocazione", en Altri studi sulla cassazione civile, sui vizi della sentenza e sulle impugnazioni, Opere giuridiche di Piero Calamandrei (Roma, RomaTRE Press, vol. VIII) pp. 483-486.

Carbonell, Flavia (2015): "Sobre la idea de decisión judicial correcta", Analisi e diritto, No 2015: pp. 11-46.

Carbonell, Flavia, y Letelier, Raúl (2020): “Debido proceso y garantías jurisdiccionales", en Contreras, Pablo, y Salgado, Constanza (eds.): Curso de derechos fundamentales (Santiago, Tirant Lo Blanch) pp. 345-378.

Couture, Eduardo (1958): Fundamentos del derecho procesal civil (Buenos Aires, Depalma, tercera edición).

Duarte D'Almeida, Luis (2015a): "Defining 'Defences", en Dyson, Andrew: Goudkamp, James; Wilmot-Smith, Frederick (eds.), Defences in Tort (Oxford, Hart Publishing) pp. 35-52.

Duarte D'Almeida, Luis (2015b): Allowing for Exceptions: A Theory of Defences and Defeasibility in Law (Oxford, Oxford University Press).

Duce, Mauricio (2015a): "La condena de inocentes en Chile: una aproximación empírica a partir de los resultados de los recursos de revisión acogidos por la Corte Suprema en el periodo 2007-2013", Política Criminal, vol. 10, No 19: pp. 159-191.

Duce, Mauricio (2015b): "Algunas lecciones a partir de cuatro casos de condena de inocentes en Chile", Revista de Derecho (Coquimbo), vol. 22, No 1: pp. 149-208.

DuCE, Mauricio (2017): "Los recursos de revisión y la condena de inocentes en Chile: Una Aproximación Empírica en el Período 2007-2016”, Revista Doctrina y Jurisprudencia Penal, No 30: pp. 3-40. 
Duce, Mauricio (2018): "Prueba pericial y su impacto en los errores del sistema de justicia penal: antecedentes comparados y locales para iniciar el debate", Revista Ius et Praxis, Año 24, No 2: pp. 223-262.

Fernández, José Manuel, y Olavarría, Malva (2018): "Examinando de nuevo la acción de revisión”, Política criminal, vol. 13, № 26: pp. 1190-1285.

Fernández, Mercedes (2005): Prueba y presunción de inocencia (Madrid, Iustel).

Ferrer, Jordi (2007): La valoración racional de la prueba (Madrid, Marcial Pons).

FERRER, Jordi (2010): "Una concepción minimalista y garantista de la presunción de inocencia”, Revista De La Maestría En Derecho Procesal, vol. 4, No 1: pp. 1-26.

FERrER, Jordi (2018): "Prolegómenos para una teoría de los estándares de prueba”, en Papayannis, Diego, y Pereira, Esteban (eds.) Filosofía del derecho privado (Madrid, Marcial Pons) pp. 401-430.

Fletcher, G. (1969): “Two Kinds of Legal Rules: A Comparative Study of Burden-of-Persuasion Practices in Criminal Cases", The Yale Law Journal, vol. 77, No 5: pp. 880-935.

Gardner, John (2004): "Fletcher on Offences and Defences", Tulsa Law Review, vol. 39: pp. 817-827.

Gardner, John (2007) [2002]: "In Defence of Defences", en Gardner, John, Offences and Defences: Selected Essays in the Philosophy of Criminal Law (Oxford, Oxford University Press) pp. 77-89.

Gascón, Marina (2013): "Prueba científica. Un mapa de retos", en VázQuez, Carmen (ed.), Estándares de prueba y prueba cientifica. Ensayos de epistemología jurídica (Barcelona, Marcial Pons) pp. 181-203.

GonZÁlez Lagier, Daniel (2007): "Hechos y conceptos", Cuadernos electrónicos de filosofía del derecho, No 15.

GonzÁlez Lagier, Daniel (2014): "Presunción de inocencia, verdad y objetividad", en García Amado, Juan Antonio y Bonorino, Pablo Raúl (coords.) Prueba y razonamiento probatorio en el derecho. Debates sobre abducción (Granada, Comares) pp. 85-117.

GonZÁlez Lagier, Daniel (2020): “¿Es posible formular un estándar de prueba preciso y objetivo? Algunas dudas desde un enfoque argumentativo de la prueba”, en Revista Telemática de Filosofía del Derecho, No 23: pp. 79-97.

Hart, Herbert Lionel Adolphus (2008) [1957]: “Legal Responsibility and Excuses”, en Punishment and Responsibility: Essays in the Philosophy of Law (Oxford, Oxford University Press) pp. 28-53.

Hart, Herbert Lionel Adolphus (1949): "The Adscription of Responsibility and Rights", en Proceedings of the Aristotelian Society, vol. 49: pp. 171-194.

Horvitz, María Inés y López, Julián (2002): Derecho procesal penal chileno (Santiago, Editorial Jurídica de Chile, tomo I).

Jeffries, John Calvin; Stephan, Paul B. (1979): "Defenses, Presumptions, and Burden of Proof in the Criminal Law", The Yale Law Journal, vol. 88, No 7: pp. 1325-1407.

LaUdAn, Larry (2005): “The presumption of innocence: Material or Probatory?”, Legal Theory, No 11: pp. 333-361.

Mañalich, Juan Pablo (2007): "La pena como retribución”, Revista de Estudios Públicos, No 108: pp. 117-205. 
Mañalich, Juan Pablo (2010): "Retribución como coacción punitiva”, Derecho y Humanidades, No 16, vol. 1, pp. 49-67.

MaÑalich, Juan Pablo (2020): "Justicia, procedimiento y acción de revisión. El principio de culpabilidad frente a la cosa juzgada”, Ius et Praxis, año 26, № 1: pp. 28-56.

Maturana, Cristián, y Mosquera, Mario (2018): Los recursos procesales (Santiago, Editorial Jurídica de Chile, tercera edición).

McNaughton, John T. (1955): "Burden of Production of Evidence: A Function of a Burden of Persuasion", Harvard Law Review, vol. 68, No 8: pp. 1382-1391.

Moore, Michael S. (2010): Placing Blame: A General Theory of Criminal Law (Oxford, Oxford University Press).

Ortells, Manuel (2001): Derecho Procesal Civil (Madrid, Aranzadi, octava edición).

PAILLÁs, Enrique (2011): La revisión en materia penal (Santiago, LexisNexis).

Rodríguez, Ignacio (2015): Procedimiento civil. Juicio ordinario de mayor cuantía (Santiago, Editorial Jurídica de Chile).

Stoenrel, Carlos Alberto (1995): De las disposiciones comunes a todo procedimiento y de los incidentes (Santiago, Editorial Jurídica de Chile).

TARuffo, Michele (2005): "Conocimiento científico y estándares de prueba judicial", Boletín Mexicano de Derecho Comparado, año XXXVIII, No 114: pp. 1285-1312.

Toulmin, Stephen (1958): The Uses of Argument (Cambridge, Cambridge University Press)

VAlenZuela, Jonatan (2013): "Inocencia y razonamiento probatorio", Revista de Estudios de la Justicia, No 18: pp. 13-23.

ValenZuela, Jonatan (2017): Hechos, pena y proceso. Ensayo sobre racionalidad y prueba en el derecho procesal penal chileno (Santiago, Rubicón Editores).

VÁzQuez, Carmen (2015): De la prueba científica a la prueba pericial (Madrid, Marcial Pons).

Wróblewski, Jerzy (1974): "Legal Syllogism and Rationality of Judicial Decision", Rechtstheorie, No 1: pp. 33-46.

\section{NORMAS CITADAS}

Código Civil de Chile (31/5/1856).

Código de Procedimiento Civil de Chile (30/8/1902).

Código Penal de Chile (12/11/1874).

Código Procesal Penal de Chile (12/10/2000).

Convención Americana de Derechos Humanos, San José, Costa Rica (22 de noviembre de 1969).

Pacto Internacional de Derechos Políticos y Civiles, Nueva York, Estados Unidos (16 de diciembre de 1966).

\section{JURISPRUDENCIA CONSULTADA}

Sin indicación de partes (2012): Corte Suprema, 23 de febrero (revisión) Resolución No 17328 en Vlex, Fecha de consulta 16 de enero de 2020. 
A.A.S. (2012): Corte Suprema, 23 de febrero (revisión) Resolución No 17326 en Vlex, Fecha de consulta 16 de enero de 2020.

Sin INDICACIÓN DE PARTES (2012): Corte Suprema, 5 de abril (revisión) Resolución No 27515 en Vlex, Fecha de consulta 16 de enero de 2020.

Sin INDiCACión de partes (2012): Corte Suprema, 5 de abril (revisión) Resolución No 27518 en Vlex, Fecha de consulta 16 de enero de 2020.

FISCAL REGIONAL SUBROGANTE DEL MINISTERIO PÚBLICO CON TRIBUNAL DE JUICIO ORAL EN EL PENAL $D E$ ANGOL (2012): Corte Suprema, 7 de mayo (revisión) Resolución No 35277 en Vlex, Fecha de consulta 16 de enero de 2020.

FISCAL REGIONAL DE LA ZONA METROPOLITANA CENTRO NORTE CON 6 JUZGADO DE GARANTIA DE SANTIAGO (2012): Corte Suprema, 14 de mayo (revisión) Resolución No 37739 en Vlex, Fecha de consulta 17 de enero de 2020.

FISCAL REGIONAL DE LA ZONA METROPOLITANA CENTRO NORTE CON 7 JUZGADO DE GARANTÍA DE SANTIAGO (2012): Corte Suprema, 14 de mayo (revisión) Resolución No 37730 en Vlex, Fecha de consulta 17 de enero de 2020.

FISCAL REGIONAL DE LA ZONA METROPOLITANA OCCIDENTE CON 1 JUZGADO DE GARANTÍA DE SANTIAGO (2012): Corte Suprema, 14 de mayo (revisión) Resolución No 37755 en Vlex, Fecha de consulta 17 de enero de 2020.

FISCAL REGIONAL DEL MINISTERIO PÚBLICO DE LA ZONA METROPOLITANA OCCIDENTE CON 9 JUZGADO DE GARANTÍA DE SANTIAGO (2012): Corte Suprema, 14 de mayo (revisión) Resolución No 37719 en Vlex, Fecha de consulta 17 de enero de 2020.

FISCAL REGIONAL DE LA ZONA METROPOLITANA OCCIDENTE CON 9 JUZGADO DE GARANTÍA DE SANTIAGO (2012): Corte Suprema, 14 de mayo (revisión) Resolución No 37800 en Vlex, Fecha de consulta 17 de enero de 2020.

DEFENSORÍa PENAL PÚBLICA CON JUZGADO DE GARANTÍA DE QUILPUÉ (2012): Corte Suprema, 6 de septiembre (revisión) Resolución No 73632 en Vlex, Fecha de consulta 17 de enero de 2020.

FisCAL REGIONAL CON 9 JUZGADO DE GARANTÍA DE SANTIAGO (2012): Corte Suprema, 10 de septiembre (revisión) Resolución No 74804 en Vlex, Fecha de consulta 17 de enero de 2020.

FISCAL REGIONAL DE LA ZONA METROPOLITANA CENTRO NORTE CON 6 JUZGADO DE GARANTÍA DE SANTIAGO (2012): Corte Suprema, 11 de octubre (revisión) Resolución No 83567 en Vlex, Fecha de consulta 20 de enero de 2020.

FisCAL REGIONAL CON JUZGADO DE GARANTÍA DE SAN BERNARDO (2013): Corte Suprema, 23 de enero (revisión) Resolución No 7312 en Vlex, Fecha de consulta 20 de enero de 2020.

J.E.S.B. CON 8 JUZGADO DE GARANTIA DE SANTIAGO (2013): Corte Suprema, 18 de febrero (revisión) Resolución No 11832 en Vlex, Fecha de consulta 20 de enero de 2020.

W.B.B. (2013): Corte Suprema, 2 de abril (revisión) Resolución No 20740 en Vlex, Fecha de consulta 20 de enero de 2020.

M.I.P.M. CON 1 JUZGADO DE POLICÍA LOCAL DE LA FLORIDA (2013): Corte Suprema, 28 de mayo (revisión) Resolución No 35247 en Vlex, Fecha de consulta 20 de enero de 2020.

G.D.R. CON tRibunal oral en lo PENAL DE Colina (2013): Corte Suprema, 4 de julio (revisión) Resolución No 44915 en Vlex, Fecha de consulta 20 de enero de 2020. 
Defensoría PENAL PÚbLICA CON 7 JUZGAdo dE GARANTÍA DE SANTIAGO (2013): Corte Suprema, 22 de agosto (revisión) Resolución No 58413 en Vlex, Fecha de consulta 21 de enero de 2020.

FISCAL REGIONAL DE LA ZONA METROPOLITANA CENTRO NORTE CON 5 JUZGADO DE GARANTÍA DE SANTIAGO (2013): Corte Suprema, 19 de noviembre (revisión) Resolución No 102653 en Vlex, Fecha de consulta 21 de enero de 2020.

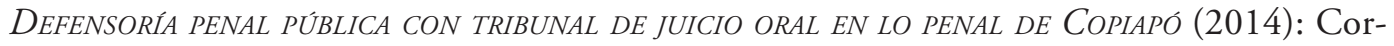
te Suprema, 14 de enero (revisión) Resolución No 11126 en Vlex, Fecha de consulta 21 de enero de 2020.

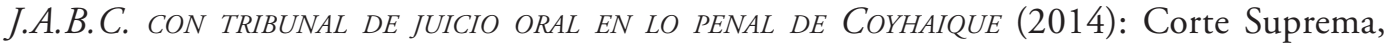
30 de enero (revisión) Resolución No 24485 en Vlex, Fecha de consulta 21 de enero de 2020 .

C.A.G.G. CON $1^{\circ}$ TRIBUNAL DE JUICIO ORAL EN LO PENAL DE SANTIAGO (2014): Corte Suprema, 15 de abril (revisión) Resolución No 68808 en Vlex, Fecha de consulta 21 de enero de 2020.

C.G.R. CON tRibunal DE JUiCio oral en lo PENAL TALAGANTE (2014): Corte Suprema, 15 de abril (revisión) Resolución No 68811 en Vlex, Fecha de consulta 21 de enero de 2020.

L. y J.D.C. CON $14^{\circ}$ JUZGADO DE GARANTÍA DE SANTIAGO (2014): Corte Suprema, 15 de abril (revisión) Resolución No 68810 en Vlex, Fecha de consulta 21 de enero de 2020.

M.C.S. con tribunal de JUICIO ORAL EN LO PENAL DE TALCA (2014): Corte Suprema, 15 de abril (revisión) Resolución No 68798 en Vlex, Fecha de consulta 21 de enero de 2020.

G.M.L. CON TRIBUNAL DE JUICIO ORAL EN LO PENAL DE SANTA CRUZ (2014): Corte Suprema, 28 de abril (revisión) Resolución No 78435 en Vlex, Fecha de consulta 22 de enero de 2020 .

J.R.L. CON TRIBUNAL DE JUICIO ORAL EN LO PENAL DE LOS ANDES (2014): Corte Suprema, 28 de abril (revisión) Resolución No 78417 en Vlex, Fecha de consulta 22 de enero de 2020.

C.G.G. CON $1^{\circ}$ tribunal de JUicio oral en lo Penal de SANTiago (2014): Corte Suprema, 5 de mayo (revisión) Resolución No 85290 en Vlex, Fecha de consulta 22 de enero de 2020 .

N.R.A. CON TRIBUNAL DE JUICIO ORAL EN LO PENAL VIÑA DEL MAR (2014): Corte Suprema, 5 de mayo (revisión) Resolución No 85389 en Vlex, Fecha de consulta 22 de enero de 2020.

A.A.V. CON TRIBUNAL DE JUICIO ORAL EN LO PENAL DE TALCA (2014): Corte Suprema, 11 de junio (revisión) Resolución No 114925 en Vlex, Fecha de consulta 22 de enero de 2020.

C.R. CON $7^{\circ}$ TRIBUNAL DE JUICIO ORAL EN LO PENAL DE SANTIAGO (2014): Corte Suprema, 11 de junio (revisión) Resolución No 115104 en Vlex, Fecha de consulta 22 de enero de 2020.

M.V.G. CON TRIBUNAL DE JUICIO ORAL EN LO PENAL DE TALCA (2014): Corte Suprema, 11 de junio (revisión) Resolución No 115097 en Vlex, Fecha de consulta 22 de enero de 2020.

A.M.O. con tRibunal de JUICIO ORAL EN LO PENAL DE LOS ANDES (2014): Corte Suprema, 24 de septiembre (revisión) Resolución No 216222 en Vlex, Fecha de consulta 22 de enero de 2020 . 
C.M.P. con $\sigma^{\circ}$ tribunal de JUicio oral en lo PENAL de SAN Miguel (2014): Corte Suprema, 2 de octubre (revisión) Resolución No 220997 en Vlex, Fecha de consulta 22 de enero de 2020.

J.M. y A.H.T.J. CON TRIBUNAL DE JUICIO ORAL EN LO PENAL DE ANGOL (2014): Corte Suprema, 2 de octubre (revisión) Resolución No 221103 en Vlex, Fecha de consulta 22 de enero de 2020.

J.P.P. CON tRibunal DE JUicio oRAL EN LO PENAL DE ANTOFAGASTA (2014): Corte Suprema, 2 de octubre (revisión) Resolución No 220998 en Vlex, Fecha de consulta 22 de enero de 2020.

M.B.F. CON tRibunal de JUICIO ORAL en lo PENAL TALAGANTE (2014): Corte Suprema, 2 de octubre (revisión) Resolución No 220982 en Vlex, Fecha de consulta 22 de enero de 2020.

C.A.J. con tRIbunal de JUicio oral en lo PENAL DE Quillota (2014): Corte Suprema, 15 de octubre (revisión) Resolución No 227326 en Vlex, Fecha de consulta 23 de enero de 2020.

FISCAL REGIONAL DE LA ZONA METROPOLITANA SUR CON 12 TRIBUNAL DE JUICIO ORAL EN LO PENAL DE SANTiago (2014): Corte Suprema, 21 de octubre (revisión) Resolución No 233589 en Vlex, Fecha de consulta 23 de enero de 2020.

FISCAL REGIONAL DE LA ZONA METROPOLITANA ORIENTE CON 7 TRIBUNAL DE JUICIO ORAL EN LO PENAL DE SANTIAGO (2015): Corte Suprema, 31 de marzo (revisión) Resolución No 46591 en Vlex, Fecha de consulta 23 de enero de 2020.

FISCAL REGIONAL DE LA ZONA METROPOLITANA CENTRO NORTE CON 7 JUZGADO DE GARANTÍA DE SANTIAGO (2016): Corte Suprema, 3 de mayo (revisión) Resolución No 236776 en Vlex, Fecha de consulta 23 de enero de 2020.

A.A.S.M. con tribunal de JUiCio oral en lo Penal de TALCA (2016): Corte Suprema, 5 de julio (revisión) Resolución No 360487 en Vlex, Fecha de consulta 23 de enero de 2020.

M.Á.G.D. CON 7 JUZGADO DE GARANTÍA DE SANTIAGO (2017): Corte Suprema, 3 de abril (revisión) Resolución No 124076 en Vlex, Fecha de consulta 23 de enero de 2020.

FISCAL REGIONAL DE LA ZONA METROPOLITANA CENTRO NORTE CON 7 JUZGADO DE GARANTÍA DE SANTIAGO (2017): Corte Suprema, 5 de abril (revisión) Resolución No 126942 en Vlex, Fecha de consulta 23 de enero de 2020.

M.I.B. DEL S. CON JUZGado DE GaRANTía DE Villa Alemana (2017): Corte Suprema, 24 de abril (revisión) Resolución No 195356 en Vlex, Fecha de consulta 24 de enero de 2020.

R.E.L.R CON JUZGADO DE POLICÍA LOCAL DE LA UNIÓN (2017): Corte Suprema, 31 de julio (revisión) Resolución No 357414 en Vlex, Fecha de consulta 24 de enero de 2020.

Defensoría penal pública con JuZgado de garantía DE S.J. (2018): Corte Suprema, 5 de marzo (revisión) Resolución No 27 en Vlex, Fecha de consulta 24 de enero de 2020.

R.R.A.C. con tribunal oral en lo penal de LA Serena (2019): Corte Suprema, 4 de marzo (revisión) Rol de ingreso: 26070/2018 en Vlex, Fecha de consulta 24 de enero de 2020.

DEFENSORÍA PENAL PÚBLICA CON TRIBUNAL ORAL EN LO PENAL DE C. (2019): Corte Suprema, 25 de abril (revisión) Rol de ingreso: 12664/2018 en Vlex, Fecha de consulta 24 de enero de 2020 . 
PÉREZ CON FisCALÍa (2019): Corte Suprema, 3 de septiembre (revisión) Rol de ingreso: 16570/2018 en Vlex, Fecha de consulta 24 de enero de 2020.

ARMENDÁRIZ CON VALDEBENITO (2019): Corte Suprema, 10 de septiembre (revisión) Rol de ingreso 9485/2019 en Vlex, Fecha de consulta 24 de enero de 2020.

ARMENDÁRIZ CON VALDEBENITO (2019): Corte Suprema, 10 de septiembre (revisión) Rol de ingreso: 9486/2019 en Vlex, Fecha de consulta 28 de enero de 2020.

ARMENDARIZ CON VALDEBENITO (2019): Corte Suprema, 10 de septiembre (revisión) Rol de ingreso: 9487/2019 en Vlex, Fecha de consulta 28 de enero de 2020.

Ministerio Publico (2019): Corte Suprema, 2 de octubre (revisión) Rol de ingreso: 9760/2019 en Vlex, Fecha de consulta 28 de enero de 2020.

PRovidel con tRibunal oral en lo penal Rancagua (2019): Corte Suprema, 24 de octubre (revisión) Rol de ingreso: 18580/2019 en Vlex, Fecha de consulta 28 de enero de 2020.

Ministerio Público con tribunal de letras y garantía de Pozo Almonte (2019): Corte Suprema, 23 de diciembre (revisión) Rol de ingreso: 11671/2019 en Vlex, Fecha de consulta 28 de enero de 2020.

ARMENDÁRIZ CON ORTEGA (2020): Corte Suprema, 11 de marzo (revisión) Rol de ingreso: 17311/2019 en Vlex, Fecha de consulta 08 de mayo de 2020. 